\title{
Damping Capacity in Fe-Mn Binary Alloys
}

\author{
Young-Kook LEE, Joong-Hwan JUN and Chong-Sool CHOI
}

Department of Metallurgical Engineering, Yonsei University, 134 Shinchon-dong, Seodaemun-ku, Seoul 120-749, Korea.

(Received on April 3, 1997; accepted in final form on June 20, 1997)

\begin{abstract}
The damping capacities of Fe-Mn binary alloys have been investigated in a wide range of manganese content from 5 to $30 \mathrm{wt} \%$. The damping capacity increases with increasing manganese content, attains a maximum at approximately $17 \mathrm{wt} \% \mathrm{Mn}$, and decreases with further manganese content. It is suggested that the damping mechanisms of Fe-Mn alloys containing $\gamma$ and $\varepsilon$ phases are the stress-induced movement of the defects: stacking fault boundary in $\gamma$, stacking fault boundary in $\varepsilon, \varepsilon$ martensite variant boundary, $\gamma / \varepsilon$ interphase boundary. The appearance of the maximum damping capacity at around $17 \mathrm{wt} \% \mathrm{Mn}$ in $\mathrm{Fe}-\mathrm{Mn}$ binary system is well explained with the damping mechanisms. The contributions of the damping mechanisms to the overall damping capacities of $\mathrm{Fe}-17 \mathrm{wt} \% \mathrm{Mn}$ and $\mathrm{Fe}-21 \mathrm{wt} \% \mathrm{Mn}$ alloys are quantitatively analyzed, which indicates that $\varepsilon$ martensite bears the major part of their damping capacities.
\end{abstract}

KEY WORDS: damping capacity; Fe-Mn alloys; austenite; $\varepsilon$ martensite; $\gamma / \varepsilon$ interphase; stacking fault; $\varepsilon$ martensite variant.

\section{Introduction}

Machine designers have long sought to decrease the noise and vibration arising from moving metallic parts in machines and vehicles. One solution has been to employ materials with high damping capacity in manufacture of such components in order to keep the noise and vibration to a minimum. A large number of alloys with high damping capacity, such as $\mathrm{Mn}-\mathrm{Cu},{ }^{11} \mathrm{Cu}-\mathrm{Al}-$ $\mathrm{Ni},{ }^{2)} \mathrm{Ni}-\mathrm{Ti},{ }^{3)} \mathrm{Fe}-\mathrm{Co}-\mathrm{Mo}-\mathrm{Cr},{ }^{4)} \mathrm{Mg}-\mathrm{Zr},{ }^{5)} \mathrm{Co}-\mathrm{Ni}^{6}{ }^{6}$ and gray cast iron ${ }^{7)}$ have been developed, some of which have been used in industry. As an example, a propeller of a submarine has been made of $\mathrm{Mn}-\mathrm{Cu}$ alloy (SONOSTON). Thus, in addition to the good mechanical and corrosion properties, the vibration and noise arising from the shaft can be to a large extent dissipated within the propeller rather than being broadcast into the sea.

In a previous study ${ }^{8}$ ) we have reported that some $\mathrm{Fe}$ $\mathrm{Mn}$ alloys possess high damping capacity besides the above alloys, in which $\mathrm{Fe}-17 \mathrm{wt} \% \mathrm{Mn}$ alloy shows the best damping capacity. However, the damping mechanisms of Fe-Mn alloys have not yet been clarified, except that the damping capacity is closely related to $\varepsilon$ martensite content. ${ }^{8)}$

In the present paper, therefore, the damping capacities of $\mathrm{Fe}-\mathrm{Mn}$ alloys with manganese content from 5 to $30 \mathrm{wt} \%$ are investigated systematically as a function of manganese content, and the damping mechanisms of $\mathrm{Fe}-\mathrm{Mn}$ alloys are discussed in detail. In addition, the reason why the maximum damping capacity appears at around $17 \mathrm{wt} \% \mathrm{Mn}$ in $\mathrm{Fe}-\mathrm{Mn}$ binary system is investigated, and the damping capacities of some $\mathrm{Fe}-\mathrm{Mn}$ alloys are analyzed quantitatively on the ground of the damping mechanisms.

\section{Experimental Procedures}

$\mathrm{Fe}-\mathrm{Mn}$ alloys containing manganese content of 5 to $30 \%$ in weight were melted in vacuum by means of a high frequency induction furnace using pure electrolytic iron and electrolytic manganese, and were cast into a metallic mould. The ingots were homogenized in a protective atmosphere at $1200^{\circ} \mathrm{C}$ for $24 \mathrm{~h}$, and hotrolled to bars with diameter of about $13 \mathrm{~mm}$. From the bars, the specimens for damping capacity measurement, microstructural observation and X-ray diffraction test were prepared by rolling and machining. All the specimens were solution treated at $1050^{\circ} \mathrm{C}$ for $1 \mathrm{~h}$ and were subsequently quenched into water at room temperature.

The chemical composition and transformation temperatures of the alloys used in this study are listed in Table 1. The starting temperature of $\gamma \rightarrow \varepsilon$ martensitic transformation, $M_{\mathrm{s}}$, and the starting and finishing tem-

Table 1. Chemical composition and transformation temperatures of $\mathrm{Fe}-\mathrm{Mn}$ alloys used in this study.

\begin{tabular}{cccc|ccc}
\hline \multirow{2}{*}{ Alloy } & \multicolumn{3}{c|}{ Composition(wt\%) } & \multicolumn{3}{c}{$\begin{array}{c}\text { Transformation } \\
\text { temperatures ( }\end{array}$} \\
\cline { 2 - 7 } & $\mathrm{Mn}$ & $\mathrm{C}$ & $\mathrm{Fe}$ & $\mathrm{Ms}$ & $\mathrm{As}$ & $\mathrm{Af}$ \\
\hline $5 \mathrm{Mn}$ & 4.5 & 0.020 & bal. & & & \\
$10 \mathrm{Mn}$ & 10.1 & 0.021 & bal. & & & \\
$11 \mathrm{Mn}$ & 11.1 & 0.018 & bal. & & & \\
$13 \mathrm{Mn}$ & 13.4 & 0.025 & bal. & 181 & 226 & 271 \\
$16 \mathrm{Mn}$ & 16.2 & 0.028 & bal. & 151 & 206 & 252 \\
$17 \mathrm{Mn}$ & 17.0 & 0.019 & bal. & 142 & 200 & 245 \\
$18 \mathrm{Mn}$ & 18.4 & 0.023 & bal. & & & \\
$21 \mathrm{Mn}$ & 21.3 & 0.021 & bal. & 102 & 182 & 228 \\
$23 \mathrm{Mn}$ & 23.0 & 0.018 & bal. & 82 & 168 & 214 \\
$25 \mathrm{Mn}$ & 25.3 & 0.020 & bal. & & & \\
$28 \mathrm{Mn}$ & 27.8 & 0.021 & bal. & & & \\
$30 \mathrm{Mn}$ & 29.5 & 0.020 & bal. & & & \\
\hline
\end{tabular}


peratures of its reverse transformation, $A_{\mathrm{s}}$ and $A_{\mathrm{f}}$, were determined by a dilatometer. For the evaluation of volume fraction of each constituent phase contained in the alloys, X-ray diffraction test was conducted. Using the integrated intensities of $\varepsilon(10 \cdot 1), \gamma(200)$ and $\alpha^{\prime}(110)$, the volume fractions of $\varepsilon$ martensite, $\gamma$ austenite and $\alpha^{\prime}$ martensite in the alloys were evaluated. ${ }^{9,10}$ )

The damping capacity was measured using FöpplePertz type torsional pendulum appratus ${ }^{11)}$ made in our laboratory. The damping specimen was $186 \mathrm{~mm}$ in total length, $7 \mathrm{~mm}$ in gauge diameter, and $157 \mathrm{~mm}$ in gauge length, and was vibrated freely at frequency of about $12 \mathrm{~Hz}$. The damping capacity was represented in the logarithmic decrement $(\delta)$ defined as Eq. (1):

$$
\delta=\ln \left(\frac{a_{n}}{a_{n+1}}\right)
$$

where $a_{n}$ and $a_{n+1}$ represent $n$th and $n+1$ th strain amplitude, respectively.

Specimens for optical metallography were electropolished in a solution of $90 \% \mathrm{CH}_{3} \mathrm{COOH}+10 \% \mathrm{HClO}_{4}$, and etched with a $1.2 \% \mathrm{~K}_{2} \mathrm{~S}_{2} \mathrm{O}_{5}$ acquous solution. Foils for transmission electron microscopy (TEM) were jetpolished in a $90 \% \mathrm{CH}_{3} \mathrm{COOH}+10 \% \mathrm{HClO}_{4}$ solution, and the microstructures were observed in a JEOL JEM$200 \mathrm{CX}$ operated at $160 \mathrm{kV}$.

\section{Results}

\subsection{Microstructures of As-quenched Fe-Mn Alloys}

The Fe-Mn alloys used in this study have a wide range of manganese content indicated by the black bars in Fig. 1 which was drawn by Schumann ${ }^{12)}$ using dilatometry, $\mathrm{X}$-ray diffraction and optical microscopy. Figure 2 shows the optical microstructures of $\mathrm{Fe}-\mathrm{Mn}$ alloys quenched from $1050^{\circ} \mathrm{C}$ into water at room temperature. As expected from Fig. 1, a complete $\alpha^{\prime}$ martensite was exhibited in $\mathrm{Fe}-5 \mathrm{wt} \% \mathrm{Mn}$ alloy, a mixed structure of $\varepsilon$ martensite (bright part) and $\gamma$ austenite (dark part) was shown in $\mathrm{Fe}-17 \mathrm{wt} \% \mathrm{Mn}, \mathrm{Fe}-21 \mathrm{wt} \% \mathrm{Mn}$ and $\mathrm{Fe}-25 \mathrm{wt} \% \mathrm{Mn}$ alloys, and a complete austenite structure was observed in

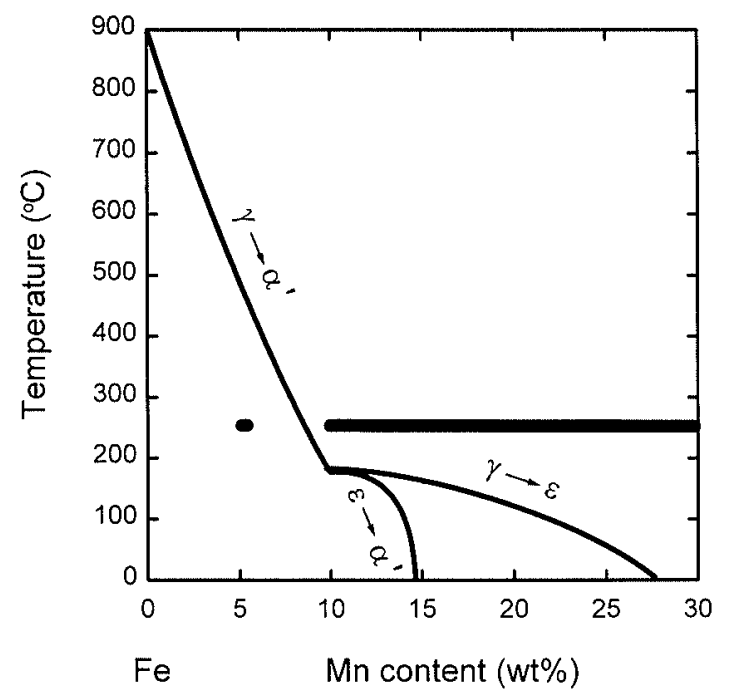

Fig. 1. The starting temperatures of martensitic transformation of $\mathrm{Fe}-\mathrm{Mn}$ alloys. ${ }^{12)}$

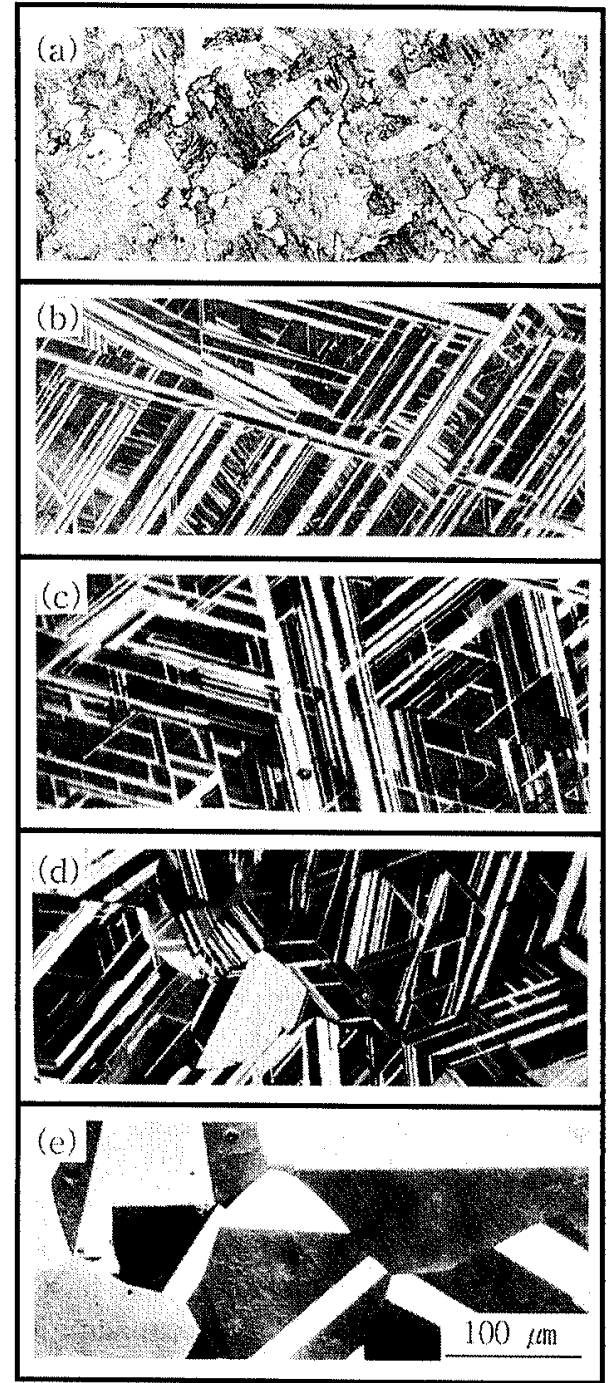

Fig. 2. Optical microstructures of $\mathrm{Fe}-\mathrm{Mn}$ alloys quenched from $1050^{\circ} \mathrm{C}$ into water at room temperature. (a) $5 \mathrm{wt} \% \mathrm{Mn}$, (b) $17 \mathrm{wt} \% \mathrm{Mn}$, (c) $21 \mathrm{wt} \% \mathrm{Mn}$, (d) $25 \mathrm{wt} \% \mathrm{Mn}$, and (e) $28 \mathrm{wt} \% \mathrm{Mn}$.

$\mathrm{Fe}-28 \mathrm{wt} \% \mathrm{Mn}$ alloy.

Figure 3 shows the typical microstructure of $\varepsilon$ martensite in Fe-Mn alloys. Although it has been well known that twelve $\varepsilon$ martensite variants can be produced according to twelve $\{111\}\langle 112\rangle$ shear system in martensitic transformation of f.c.c. to h.c.p., ${ }^{13)}$ only four differently oriented $\varepsilon$ martensite plates were observed in Fig. 3. It is considered that the four plates are probably aggregates of three $\langle 112\rangle$ variants on each plane of four different $\{111\}$ planes of $\gamma$ phase, as suggested by Wayman ${ }^{14)}$ and Takaki. ${ }^{15)}$

The volume fraction of each constituent phase determined by X-ray diffraction method ${ }^{9,10)}$ was plotted against the manganese content in Fig. 4 . The $\varepsilon$ martensite content increased with increasing the manganese content, showing a maximum value at about $17 \mathrm{wt} \% \mathrm{Mn}$, and then decreased with further manganese content. A few studies ${ }^{16-18)}$ were made on the amounts of phase constituents of $\mathrm{Fe}-\mathrm{Mn}$ binary alloys. Since austenite grain size, impurity content of interstitial element $(\mathrm{C}, \mathrm{N})$ and cooling condition (air cooling or water quenching) were different depending upon investigators, the amounts of 
phase constituents were not exactly accordant with one another. However, all the studies ${ }^{16-18)}$ including our work showed a maximum volume fraction of $\varepsilon$ martensite at approximately $17 \mathrm{wt} \% \mathrm{Mn}$ in $\mathrm{Fe}-\mathrm{Mn}$ binary system.

It has been well known that the $\gamma \rightarrow \varepsilon$ martensitic transformation occurs by passage of Shockley partial dislocations on every other (111) plane in $\gamma$ phase. ${ }^{13)}$ If the stacking fault energy of $\gamma$ phase is low, a perfect dislocation can be easily separated into two Shockley partial dislocations. Thus, it is expected that the lower the stacking fault energy, the easier the $\varepsilon$ martensitic

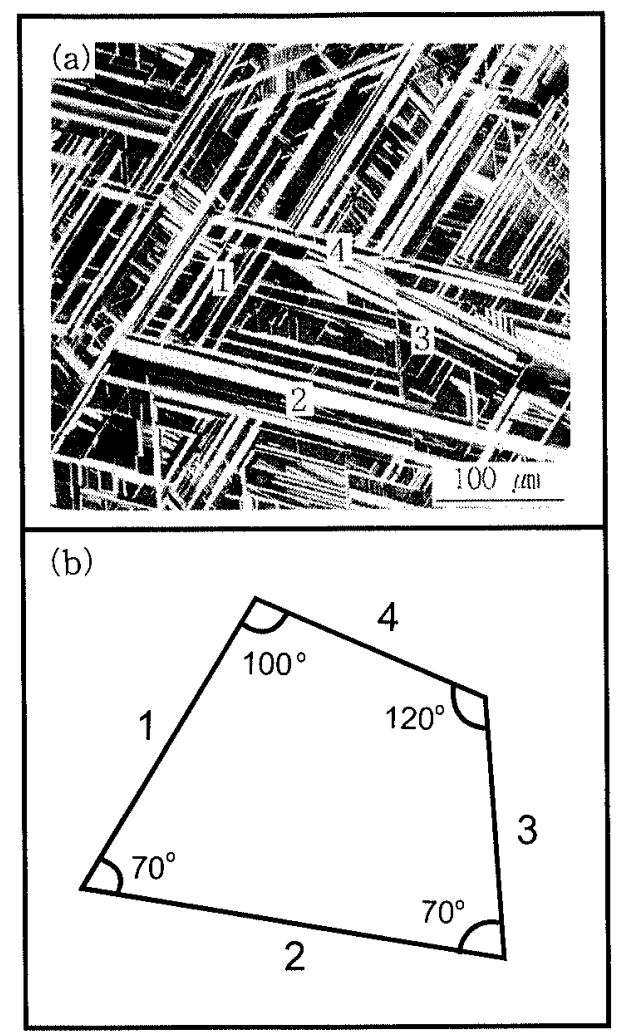

Fig. 3. Microstructure of martensite of Fe-17wt \% Mn alloy. (a) Optical micrograph of $\varepsilon$ martensite structure, and (b) Illustration of arrangement of $\varepsilon$ martensite plates

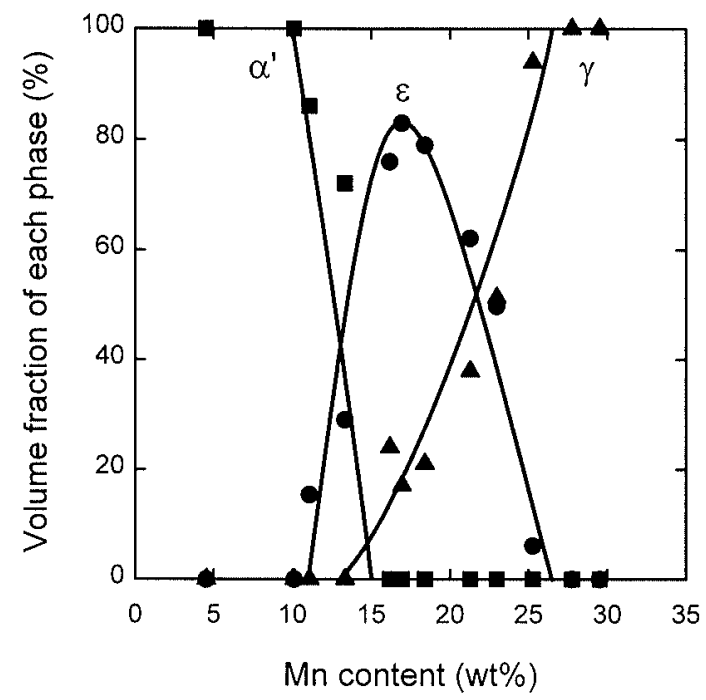

Fig. 4. Variation of volume fraction of each constituent phase with manganese content in as-quenched state of $\mathrm{Fe}-$ Mn alloys. transformation occurs. Schumann ${ }^{19)}$ has measured the stacking fault energy of $\gamma$ austenite as a function of manganese content in $\mathrm{Fe}-\mathrm{Mn}$ binary system, and reported that the stacking fault energy of $\gamma$ decreases with increasing manganese content, attains a minimum value at approximately $17 \mathrm{wt} \% \mathrm{Mn}$, and increases with further manganese content. Adler et $a l^{20)}$ have also calculated the stacking fault energy of $\mathrm{Fe}-\mathrm{Mn}$ alloys thermodynamically, and their result showed an almost same tendency as above. Therefore, it is believed that the appearance of the maximum amount of $\varepsilon$ martensite at around $17 \mathrm{wt} \% \mathrm{Mn}$ in Fig. 4 is probably caused by such a minimum stacking fault energy.

\subsection{Damping Capacities of $\mathbf{F e}-\mathrm{Mn}$ Alloys}

The damping capacities of $\mathrm{Fe}-\mathrm{Mn}$ alloys measured at a maximum surface strain, $6 \times 10^{-4}$, were plotted as a function of manganese content in Fig. 5. The damping capacity increased with increasing manganese content, showing a maximum at about $17 \mathrm{wt} \% \mathrm{Mn}$, and decreased with further manganese content. The variation of the damping capacity with manganese content shows a nearly same tendency as the variation of $\varepsilon$ martensite volume fraction shown in Fig. 4. This indicates that the damping capacities of $\mathrm{Fe}-\mathrm{Mn}$ alloys are closely related to $\varepsilon$ martensite content. In order to know the true relationship between damping capacity and $\varepsilon$ martensite content, it is necessary to investigate the damping capacity as a function of $\varepsilon$ martensite volume fraction in an $\mathrm{Fe}-\mathrm{Mn}$ alloy, because the damping capacity can be influenced by the manganese content besides $\varepsilon$ martensite content. For this purpose, $\mathrm{Fe}-17 \mathrm{wt} \% \mathrm{Mn}$ alloy was chosen, and the $\varepsilon$ volume fraction was varied in a wide range of zero to $93 \mathrm{vol} \%$. The variation of $\varepsilon$ martensite content below $83 \mathrm{vol} \%$ (as-water quenched state) was accomplished by holding the alloy at temperatures between $A_{\mathrm{s}}$ and $A_{\mathrm{f}}$ for the partial reverse martensitic transformation, $\varepsilon \rightarrow \gamma$, and subsequent cooling at $165^{\circ} \mathrm{C}$ above $M_{\mathrm{s}}$ temperature to keep the adjusted $\varepsilon$ martensite contents unchanged. Then

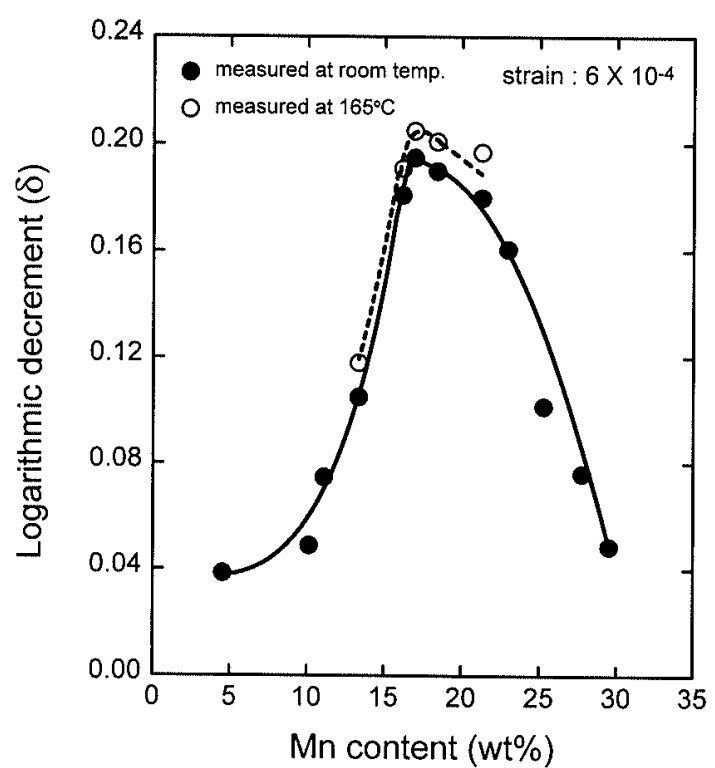

Fig. 5. Variation of damping capacity, measured at room temperature and $165^{\circ} \mathrm{C}$ respectively, with manganese content in as-quenched state of $\mathrm{Fe}-\mathrm{Mn}$ alloys. 
the damping capacity was measured at $165^{\circ} \mathrm{C}$. In this case, $\varepsilon$ martensite content was determined from the length change of the specimen associated with the reverse martensitic transformation using a dilatometer. On the other hand, the variation of $\varepsilon$ martensite volume fraction above $83 \mathrm{vol} \%$ was achieved by cooling the alloy to $-196^{\circ} \mathrm{C}$ (liquid nitrogen temperature), and then the damping capacity was measured at the same temperature as above, $165^{\circ} \mathrm{C}$. All the measured values of damping capacity were plotted as a function of $\varepsilon$ martensite volume fraction in Fig. 6. The damping capacity increased rapidly with increasing $\varepsilon$ martensite content up to about $20 \mathrm{vol} \%$, but increased gradually with further

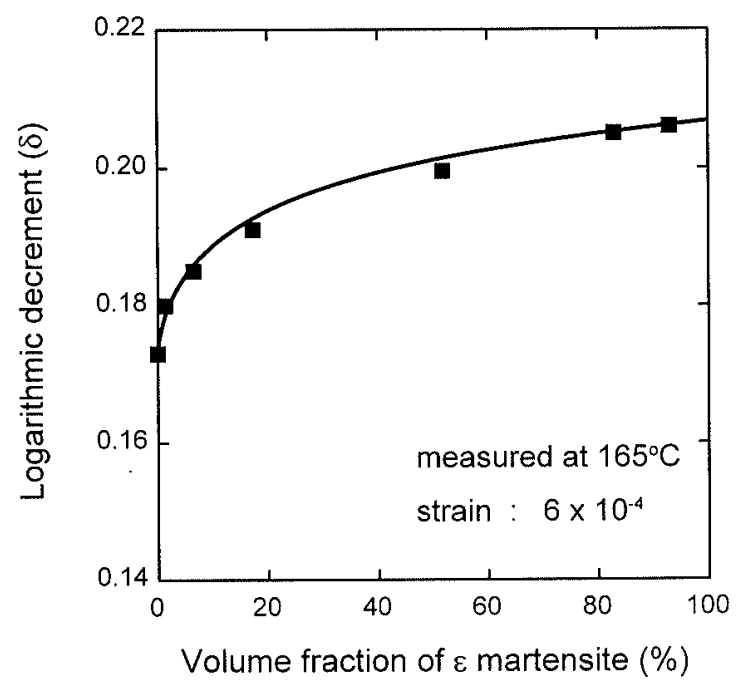

Fig. 6. Variation of damping capacity, measured at $165^{\circ} \mathrm{C}$, with the volume fraction of $\varepsilon$ martensite in $\mathrm{Fe}$-$17 \mathrm{wt} \% \mathrm{Mn}$ alloy. $\varepsilon$ martensite content.

\subsection{Microstructural Changes of Fe-Mn Alloys after Tensile Deformation}

In order to investigate the damping mechanisms of $\mathrm{Fe}-\mathrm{Mn}$ alloys, the room temperature tensile test was carried out for two specimens of $\mathrm{Fe}-17 \mathrm{wt} \% \mathrm{Mn}$ alloy with a relatively low $\varepsilon$ martensite volume fraction $(53 \mathrm{vol} \% \varepsilon)$ and a high $\&$ martensite volume fraction (90 vol\% \&) respectively, and the optical microstructures were observed before and after the tensile test (strain= $2 \%$ ). Figures 7(a) and 7(c) show the microstructures before tensile test, where the bright parts represent $\varepsilon$ martensite plates and the dark parts $\gamma$ austenite. Figures 7(b) and $7(\mathbf{d})$ show the microstructures after tensile test, where the dark plates inside the bright $\varepsilon$ parts are stressinduced $\alpha^{\prime}$ martensites which were formed at an angle of $45^{\circ}$ to the tensile direction.

As can be seen from Figs. 7(a) and 7(b), some of $\varepsilon$ martensite plates in the $53 \mathrm{vol} \% \varepsilon$ specimen became thicker after the tensile deformation. This suggests that the migration of $\gamma / \varepsilon$ interface associated with stressinduced martensitic transformation occurred under the tensile stress. On the other hand, it is observed from Figs. 7(c) and 7(d) that most of $\varepsilon$ plates were coalesced to three big blocks $(\mathrm{A}, \mathrm{B}, \mathrm{C})$ parallel to tensile direction due to their rearrangement during the tensile deformation. The coalescence of $\varepsilon$ plates similar to this phenomenon has been also reported in $\mathrm{Fe}-\mathrm{Mn}$ based alloys by other investigators. ${ }^{14,21)}$ Wayman et $a l .{ }^{14)}$ reported that the plastic deformation of $\mathrm{Fe}-13.7 \mathrm{wt} \% \mathrm{Mn}-6 \mathrm{wt} \% \mathrm{Si}-$ $8.3 \mathrm{wt} \% \mathrm{Cr}-5 \mathrm{wt} \% \mathrm{Ni}$ alloy consisting of the same phases as the $\mathrm{Fe}-17 \mathrm{wt} \% \mathrm{Mn}$ alloy was accomplished by the coalescence of $\varepsilon$ variants due to their reorientation.
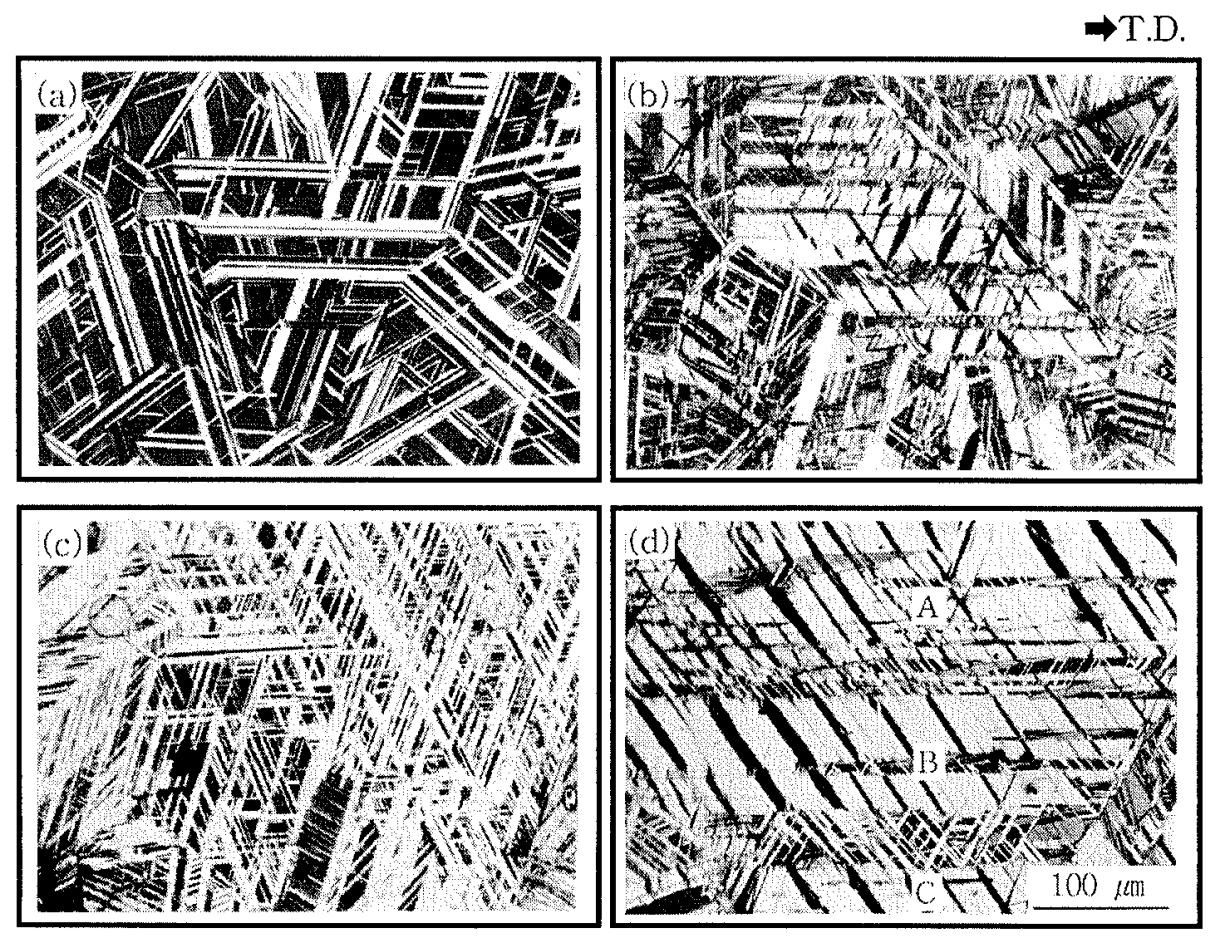

Fig. 7. Optical microstructures of the $\mathrm{Fe}-17 \mathrm{wt} \% \mathrm{Mn}$ alloy before and after $2 \%$ tensile deformation at room temperature.

(a) before deformation of a specimen with $53 \mathrm{vol} \% \varepsilon$, (b) after deformation of the specimen with $53 \mathrm{vol} \% \varepsilon$, (c) before deformation of a specimen with $90 \mathrm{vol} \% \varepsilon$, and (d) after deformation of the specimen with $90 \mathrm{vol} \% \varepsilon$. 


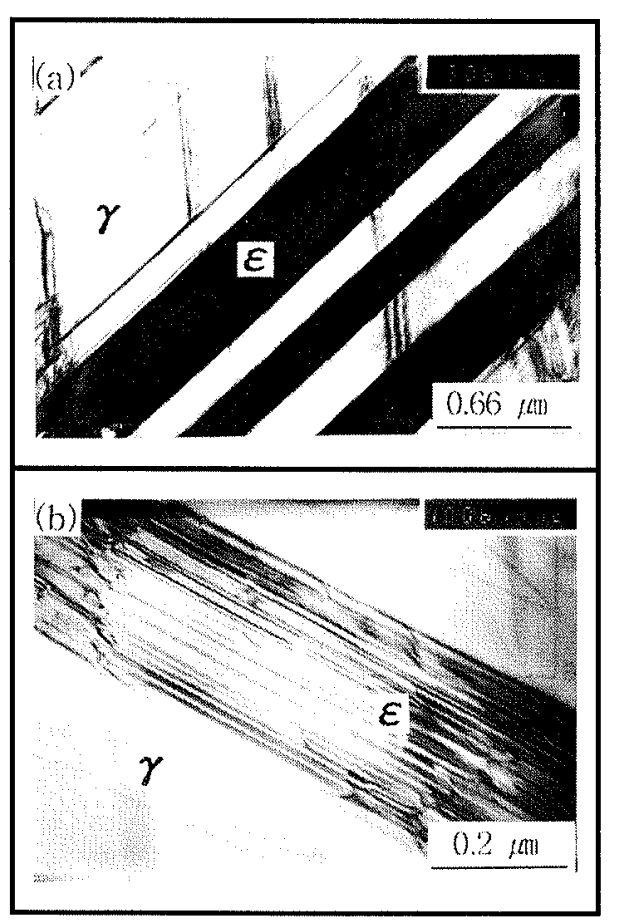

Fig. 8. Transmission electron micrographs of Fe-17wt\% $\mathrm{Mn}$ alloy.

(a) Stacking faults in $\gamma$ austenite, and

(b) Stacking faults in $\varepsilon$ martensite plate.

Recently, Jun et $a .^{21)}$ have reported that the $\varepsilon$ plates of $\mathrm{Fe}-17 \mathrm{wt} \% \mathrm{Mn}$ alloy were coalesced to big blocks elongated in parallel with the tensile direction due to the reorientation of $\varepsilon$ martensite variants, and that since the coalescence was responsible for plastic deformation, the shape memory effect (SME) of the alloy increased with increasing $\varepsilon$ martensite content above $60 \mathrm{vol} \%$.

According to transmission electron microscopy, the stacking faults were observed both in austenite and in $\varepsilon$ martensite of the Fe-17wt\% Mn alloy, as shown in Fig. 8. It seems that the average density of stacking fault in $\varepsilon$ martensite is much higher than that in the austenite.

\section{Discussion}

It has been well known that the thermoelastic martensitic alloys such as $\mathrm{Cu}-\mathrm{Al}-\mathrm{Ni},{ }^{2)} \mathrm{Ni}-\mathrm{Ti}^{3)}$ and $\mathrm{Cu}-\mathrm{Zn}-$ $\mathrm{Al}^{22)}$ exhibit high damping capacity. Xiao and Johari ${ }^{22)}$ investigated the damping mechanisms of a thermoelastic martensitic $\mathrm{Cu}-\mathrm{Zn}-\mathrm{Al}$ alloy, and suggested that the movements of the martensite variant boundary and the martensite/parent phase interface are responsible for the damping capacity of the alloy.

As shown in Fig. 7, when the two specimens of Fe$17 \mathrm{wt} \% \mathrm{Mn}$ alloy consisting of $\gamma$ and $\varepsilon$ phases were deformed in tension ( $\operatorname{strain}=2 \%$ ), the $\gamma / \varepsilon$ interphase boundaries were moved, and the $\varepsilon$ plates were coalesced to big blocks due to reorientation of $\varepsilon$ martensite variants. These phenomena are quite similar to the behaviors exhibited in the thermoelastic martensitic alloys, although it has not been known clearly to this time whether the $\mathrm{Fe}-17 \mathrm{wt} \% \mathrm{Mn}$ alloy is thermoelastic martensitic alloy or not. Thus, it is believed that the movements of the $\gamma / \varepsilon$ interphase boundaries and the $\varepsilon$ martensite variant boundaries contribute to the damping capacities of $\mathrm{Fe}-\mathrm{Mn}$ alloys containing $\gamma$ and $\varepsilon$ phases, as in case of the thermoelastic martensitic alloys.

Bruner ${ }^{23)}$ investigated the damping capacities of f.c.c. metals such as $\mathrm{Cu}, \mathrm{Al}$ and $\mathrm{Al}-0.25 \mathrm{at} \% \mathrm{Cu}$ alloy, and proposed that the damping capacities of these metals are attributed to the movement of partial dislocations constituting stacking fault boundaries. Therefore, according to Bruner's suggestion, the stacking fault boundaries observed in $\gamma$ and $\varepsilon$ in Fig. 8 can be also assumed to act as damping sources in Fe-Mn alloys containing $\gamma$ and $\varepsilon$ phases.

As a result, it is proposed that the damping mechanisms of $\mathrm{Fe}-\mathrm{Mn}$ alloys containing $\gamma$ and $\varepsilon$ phases are the movements of the following defects:

(1) $\gamma / \varepsilon$ interphase boundary

(2) $\varepsilon$ martensite variant boundary

(3) Stacking fault boundary in $\gamma$

(4) Stacking fault boundary in $\varepsilon$

Since the microstructure and the damping capacity of $\mathrm{Fe}-17 \mathrm{Wt} \% \mathrm{Mn}$ alloy were not changed even after vibration of $10^{6}$ cycles with a strain amplitude of $6 \times 10^{-4}$, it is considered that these damping sources move back and forth to comply with such a small vibrational stress corresponding to the strain, $6 \times 10^{-4}$. However, if a specimen is vibrated with a large strain amplitude almost equal to a plastic strain, the damping sources will not move back and forth but move to only one side because of introduction of dislocations which hinder the movement of the boundaries.

Meanwhile, it is insignificant to consider the damping mechanisms for $\alpha^{\prime}$ martensitic Fe-Mn alloys, since the $100 \% \alpha^{\prime}$ martensitic alloys such as $\mathrm{Fe}-5 \mathrm{wt} \% \mathrm{Mn}$ and $\mathrm{Fe}-10 \mathrm{wt} \% \mathrm{Mn}$ alloys showed very low damping capacities, as seen in Fig. 5.

Now, we can analyze the contributions of the damping mechanisms to the overall damping capacities of $\mathrm{Fe}-\mathrm{Mn}$ alloys containing $\gamma$ and $\varepsilon$ phases.

In Fig. 9 where the damping capacity of $\mathrm{Fe}-17 \mathrm{wt} \% \mathrm{Mn}$ alloy was replotted as a function of $\varepsilon$ martensite volume fraction, points $\mathrm{A}$ and $\mathrm{B}$ represent damping capacities of $100 \% \gamma$ phase and $100 \% \varepsilon$ phase, respectively. The dotted line between $\mathrm{A}$ and $\mathrm{B}$ is represented as follows:

$$
\delta_{\mathrm{c}}=\delta_{\varepsilon} \cdot f_{\varepsilon}+\delta_{\gamma} \cdot\left(1-f_{\varepsilon}\right)
$$

where $\delta_{c}$ is the damping capacity of the mixture of $\gamma$ and $\varepsilon, \delta_{\varepsilon}$ the damping capacity of $\varepsilon$ single phase, $\delta_{\gamma}$ the damping capacity of $\gamma$ single phase, $f_{\varepsilon}$ the $\varepsilon$ volume fraction, and $\left(1-f_{\varepsilon}\right)$ the $\gamma$ volume fraction since $f_{\gamma}+$ $f_{\varepsilon}=1$. Because Eq. (2) is based on the assumption that the $\gamma / \varepsilon$ interface has no influence on the damping capacity, the damping capacity expressed by the line $A B$ is due to the motion of damping sources associated with $\gamma$ and $\varepsilon$ themselves, which are stacking fault boundary in $\gamma$, stacking fault boundary in $\varepsilon$, and $\varepsilon$ martensite variant boundary, except $\gamma / \varepsilon$ interphase boundary. Since the overall damping capacity of an Fe-Mn alloy containing $\gamma$ and $\varepsilon$ phases is attributed to the movement of the four damping sources mentioned in the damping mechanisms, the difference between solid curve and dotted line in Fig. 9 corresponds to the contribution of $\gamma / \varepsilon$ 


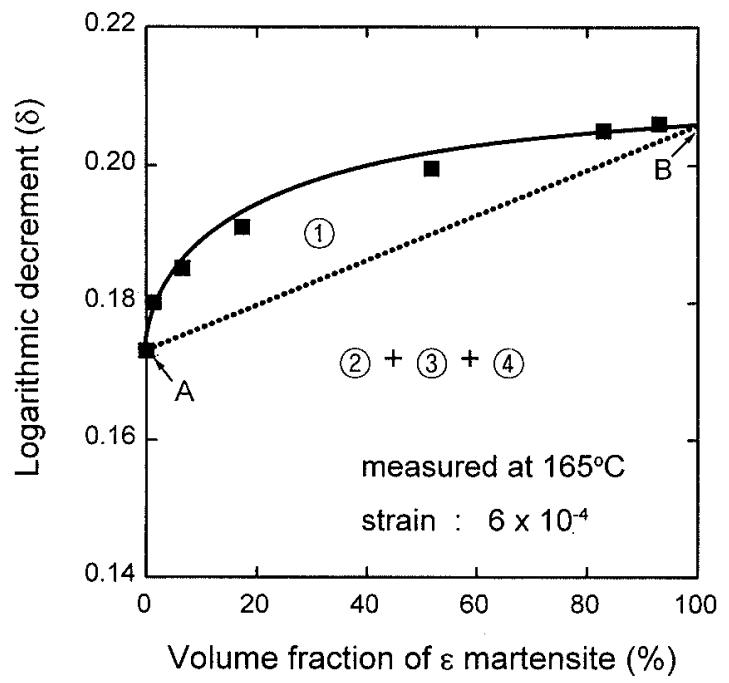

Fig. 9. Variation of damping capacity, measured at $165^{\circ} \mathrm{C}$, with the volume fraction of $\varepsilon$ martensite in $\mathrm{Fe}$ $17 \mathrm{wt} \% \mathrm{Mn}$ alloy. The damping capacity of the alloy is attributable to the movement of the four damping sources:

(1) $\gamma / \varepsilon$ interphase boundary, (2) $\varepsilon$ variant boundary, (3) stacking fault boundary in $\gamma$, and (4) stacking fault boundary in $\varepsilon$.

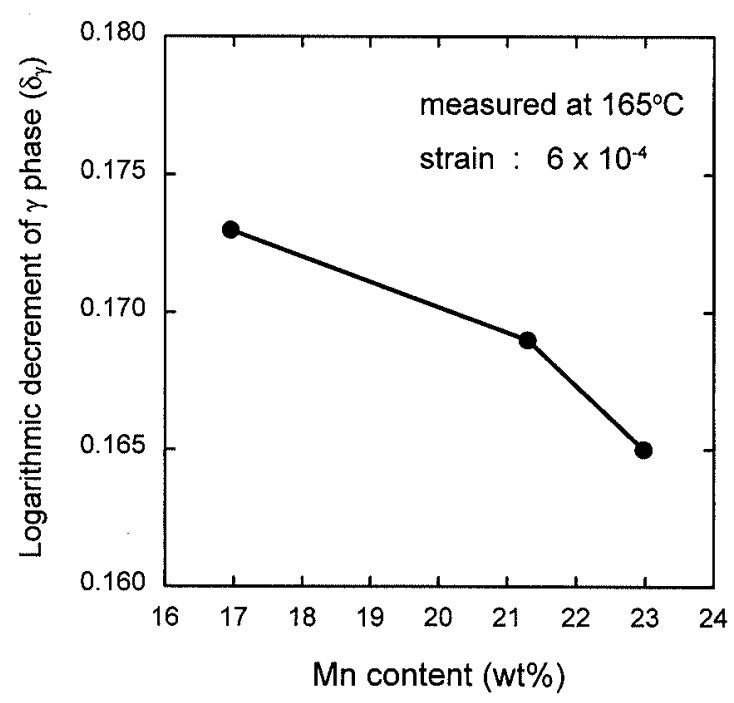

Fig. 10. Variation of damping capacity of $\gamma$ single phase, measured at $165^{\circ} \mathrm{C}$, with manganese content in $\mathrm{Fe}-$ Mn alloys.

interphase boundary to the overall damping capacity of $\mathrm{Fe}-17 \mathrm{wt} \% \mathrm{Mn}$ alloy. Consequently, the overall damping capacity, $\delta$, of an $\mathrm{Fe}-\mathrm{Mn}$ alloy composed of $\gamma$ and $\varepsilon$ phases can be represented as follows:

$$
\delta=\delta_{\mathrm{c}}+\Delta \delta_{\gamma / \varepsilon}=\delta_{\varepsilon} \cdot f_{\varepsilon}+\delta_{\gamma}\left(1-f_{\varepsilon}\right)+\Delta \delta_{\gamma / \varepsilon}
$$

or

$$
\delta=\delta_{\gamma}+\Delta \delta_{\gamma / \varepsilon}+f_{\varepsilon}\left(\delta_{\varepsilon}-\delta_{\gamma}\right)
$$

where $\Delta \delta_{y / \varepsilon}$ is the contribution of $\gamma / \varepsilon$ interphase boundary to the overall damping capacity.

The reason that $\mathrm{Fe}-17 \mathrm{wt} \% \mathrm{Mn}$ alloy shows the highest damping capacity in $\mathrm{Fe}-\mathrm{Mn}$ binary system, as shown in Fig. 5, can be explained by evaluating each term on the right of Eq. (4) for $\mathrm{Fe}-\mathrm{Mn}$ alloys.

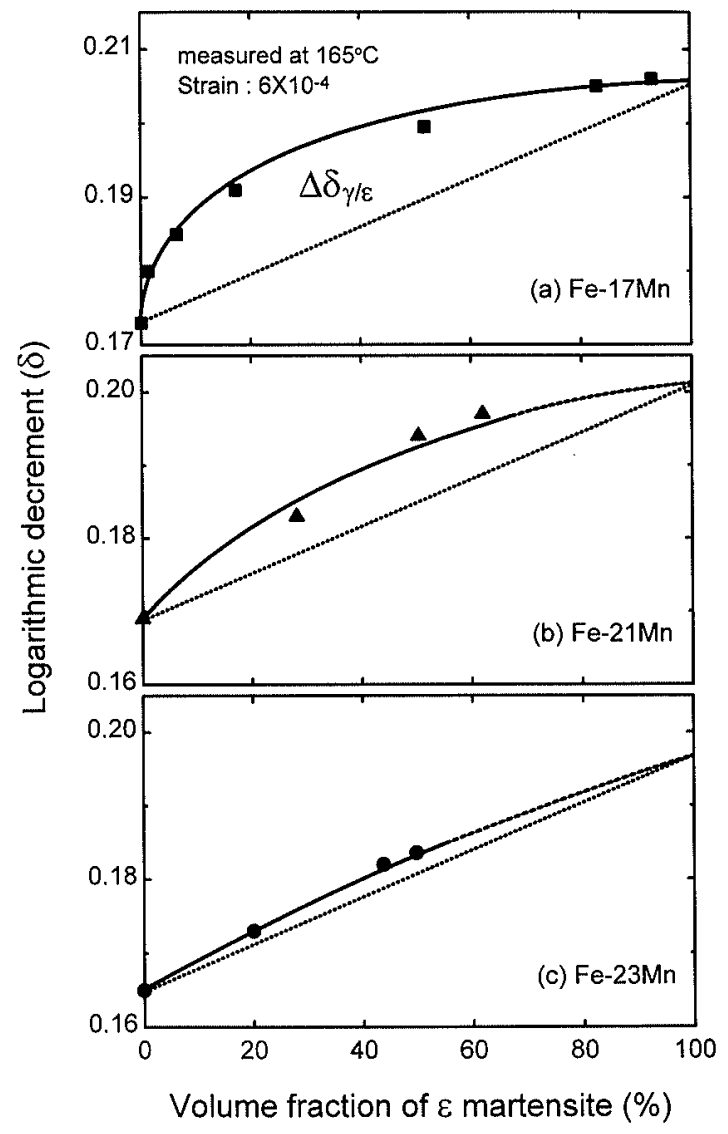

Fig. 11. Variation of damping capacity, measured at $165^{\circ} \mathrm{C}$, with the volume fraction of $\varepsilon$ martensite in $\mathrm{Fe}-$ $17 \mathrm{wt} \% \mathrm{Mn}, \mathrm{Fe}-21 \mathrm{wt} \% \mathrm{Mn}$, and $\mathrm{Fe}-23 \mathrm{wt} \% \mathrm{Mn}$ alloys.

In order to evaluate $\delta_{\gamma}$ of each $\mathrm{Fe}-\mathrm{Mn}$ alloy, the damping capacity was measured at $165^{\circ} \mathrm{C}$, after heating the alloy at $260^{\circ} \mathrm{C}$ above $A_{\mathrm{f}}$ temperature for the complete $\varepsilon \rightarrow \gamma$ reverse transformation and subsequent cooling at $165^{\circ} \mathrm{C}$ above $M_{\mathrm{s}}$ temperature to retain the reversed $\gamma$ phase. The results are shown in Fig. 10. The damping capacity of $\gamma$ single phase of $\mathrm{Fe}-17 \mathrm{wt} \% \mathrm{Mn}$ alloy was higher than those of the other two alloys. This is probably due to not only higher probability of formation of stacking fault but also easier movement of stacking fault boundary in $\mathrm{Fe}-17 \mathrm{wt} \% \mathrm{Mn}$ alloy than in the other alloys, because of its lower stacking fault energy, as reported by Schumann ${ }^{19)}$ and Adler et al. ${ }^{20)}$

To evaluate $\Delta \delta_{\gamma_{/ \varepsilon}}$, the damping capacities of some $\mathrm{Fe}$ $\mathrm{Mn}$ alloys were measured at $165^{\circ} \mathrm{C}$ as a function of $\varepsilon$ martensite volume fraction, as shown in Fig. 11. The $\Delta \delta_{\gamma / \varepsilon}$ of $\mathrm{Fe}-17 \mathrm{wt} \% \mathrm{Mn}$ alloy showed the largest value among $\mathrm{Fe}-17 \mathrm{wt} \% \mathrm{Mn}, \mathrm{Fe}-21 \mathrm{wt} \% \mathrm{Mn}$ and $\mathrm{Fe}-23 \mathrm{wt} \% \mathrm{Mn}$ alloys, at all $\varepsilon$ martensite contents. These results are well supported by the microstructures of $\mathrm{Fe}-17 \mathrm{wt} \% \mathrm{Mn}$ and $\mathrm{Fe}-$ $23 \mathrm{wt} \% \mathrm{Mn}$ alloys before and after tensile test (strain= $2 \%$ ) at room temperature (Fig. 12). The average widths of $\varepsilon$ plates of each alloy before and after tensile test, which were measured using an image analyzer, are listed in Table 2. The difference in the average width before and after tensile test was greater in $\mathrm{Fe}-17 \mathrm{wt} \% \mathrm{Mn}$ alloy than $\mathrm{Fe}-23 \mathrm{wt} \% \mathrm{Mn}$ alloy. This suggests that the moving distance of $\gamma / \varepsilon$ interphase boundary, on which $\Delta \delta_{y / \varepsilon}$ depends, is larger in the former alloy than in the latter 

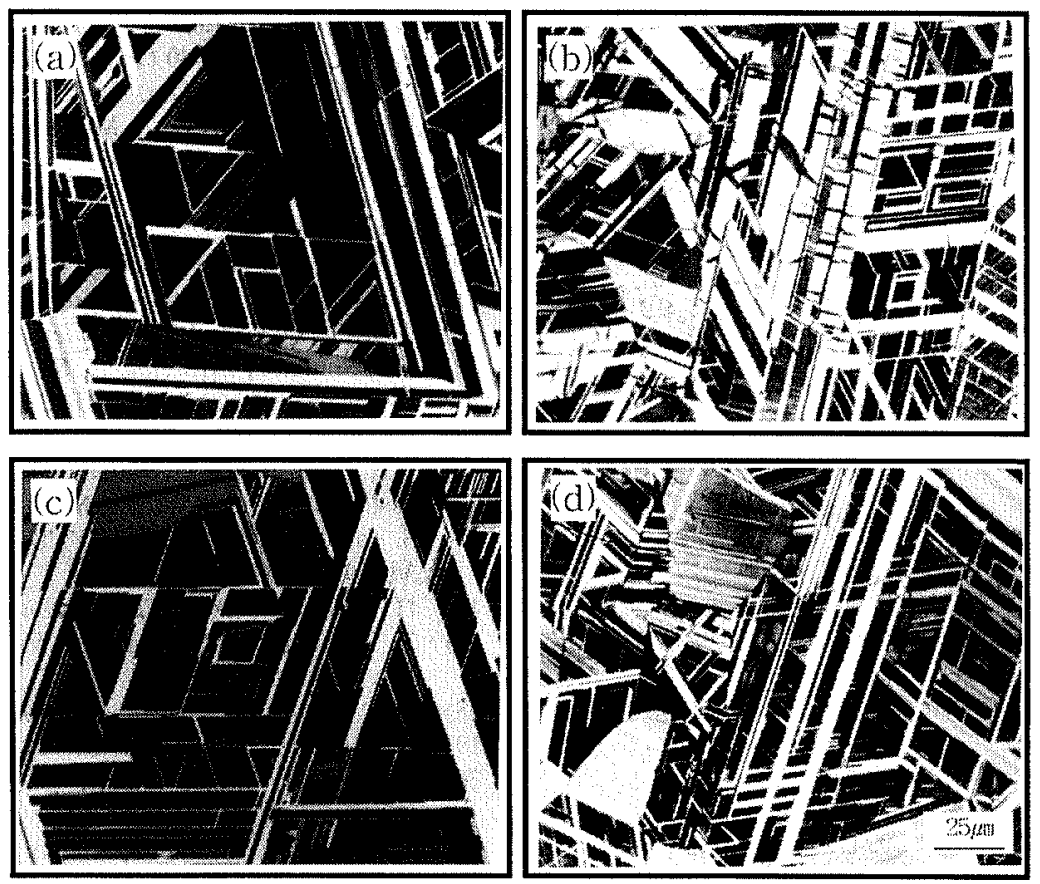

Fig. 12. Optical micrographs of the $\mathrm{Fe}-17 \mathrm{wt} \% \mathrm{Mn}$ and $\mathrm{Fe}-23 \mathrm{wt} \% \mathrm{Mn}$ alloys before and after $2 \%$ tensile deformation at room temperature.

(a) $\mathrm{Fe}-17 \mathrm{wt} \% \mathrm{Mn}$ alloy before tensile deformation, (b) $\mathrm{Fe}-17 \mathrm{wt} \% \mathrm{Mn}$ alloy after tensile deformation,

(c) $\mathrm{Fe}-23 \mathrm{wt} \% \mathrm{Mn}$ alloy before tensile deformation, and (d) $\mathrm{Fe}-23 \mathrm{wt} \% \mathrm{Mn}$ alloy after tensile deformation.

Table 2. Average widths of $\varepsilon$ martensite plates of the Fe$17 \mathrm{wt} \% \mathrm{Mn}$ and $\mathrm{Fe}-23 \mathrm{wt} \% \mathrm{Mn}$ alloys before and after $2 \%$ tensile deformation at room temperature.

\begin{tabular}{c|cc|cc}
\hline & \multicolumn{2}{|c|}{ Fe-17wt\%Mn } & \multicolumn{2}{c}{ Fe-23wt\%Mn } \\
\cline { 2 - 5 } & $\begin{array}{c}\text { Before } \\
\text { deformation }\end{array}$ & $\begin{array}{c}\text { After } \\
\text { deformation }\end{array}$ & $\begin{array}{c}\text { Before } \\
\text { deformation }\end{array}$ & $\begin{array}{c}\text { After } \\
\text { deformation }\end{array}$ \\
\hline $\begin{array}{c}\text { Average width } \\
\text { of } \varepsilon \text { plates }(\mu \mathrm{m})\end{array}$ & 1.47 & 3.38 & 0.91 & 1.76 \\
\hline
\end{tabular}

alloy during the vibration at the strain amplitude, $6 \times$ $10^{-4}$.

The values of $\left(\delta_{\varepsilon}-\delta_{\gamma}\right)$ for the $\mathrm{Fe}-\mathrm{Mn}$ alloys are almost constant regardless of manganese content, because the dotted lines of the $\mathrm{Fe}-\mathrm{Mn}$ alloys run parallel to one another, as shown in Fig. 11.

Finally, the $\varepsilon$ martensite volume fraction, $f_{\varepsilon}$, of $\mathrm{Fe}-$ $17 \mathrm{wt} \% \mathrm{Mn}$ alloy shows a maximum in Fe-Mn binary system as shown in Fig. 4.

Therefore, the reason that $\mathrm{Fe}-17 \mathrm{wt} \% \mathrm{Mn}$ alloy shows the highest damping capacity in Fe-Mn binary system is that the values of $\delta_{\gamma}, \Delta \delta_{\gamma / \varepsilon}$ and $f_{\varepsilon}$ in Eq. (4) for $\mathrm{Fe}-17 \mathrm{wt} \% \mathrm{Mn}$ alloy are larger than those for the other alloys.

Equation (3) can be rewritten as follows:

$$
\delta=\Delta \delta_{\varepsilon}+\Delta \delta_{\gamma}+\Delta \delta_{\gamma / \varepsilon}
$$

where $\Delta \delta_{\varepsilon}\left(=\delta_{\varepsilon} \cdot f_{\varepsilon}\right)$ is the damping capacity associated with $\varepsilon$ martensite itself, $\Delta \delta_{\gamma}\left(=\delta_{\gamma} \cdot f_{\gamma}\right)$ the damping capacity in response to $\gamma$ itself, and $\Delta \delta_{\gamma / \varepsilon}$ the damping capacity due to the motion of $\gamma / \varepsilon$ interphase boundary.

The contributions of the three terms to the overall damping capacity of an Fe-Mn alloy containing $\gamma$ and $\varepsilon$ phases can be analyzed quantitatively using Eq. (5) from Figs. 4 and 11 . The $\Delta \delta_{\varepsilon}$ and $\Delta \delta_{\gamma}$ are evaluated with
Table 3. Contributions of $\Delta \delta_{y}, \Delta \delta_{\varepsilon}$, and $\Delta \delta_{y / \varepsilon}$ to the overall damping capacities of $\mathrm{Fe}-17 \mathrm{wt} \% \mathrm{Mn}$ and $\mathrm{Fe}-$ $21 \mathrm{wt} \% \mathrm{Mn}$ alloys.

\begin{tabular}{c|cccccccc}
\hline Alloy & $f_{\varepsilon}$ & $\delta$ & $\Delta \delta y$ & $\Delta \delta \varepsilon$ & $\Delta \delta_{\gamma / \varepsilon}$ & $\begin{array}{c}\Delta \delta_{\gamma} \\
(\%)\end{array}$ & $\begin{array}{c}\Delta \delta \varepsilon \\
(\%)\end{array}$ & $\begin{array}{c}\Delta \delta \gamma / \varepsilon \\
(\%)\end{array}$ \\
\hline Fe-17wt\%Mn & 0.83 & 0.205 & 0.029 & 0.170 & 0.006 & 14 & 83 & 3 \\
\hline Fe-21wt\%Mn & 0.62 & 0.197 & 0.065 & 0.124 & 0.008 & 33 & 63 & 4 \\
\hline
\end{tabular}

$f_{\varepsilon}, \delta_{\varepsilon}$, and $\delta_{\gamma}$ corresponding to each alloy in Figs. 4 and 11. Then taking $\delta$ corresponding to $f_{\varepsilon}$ of each alloy in Fig. 11, the $\Delta \delta_{\gamma / \varepsilon}$ is obtained from Eq. (5) using $\Delta \delta_{\varepsilon}$ and $\Delta \delta_{\gamma}$. Table 3 shows the contributions of $\Delta \delta_{\gamma}, \Delta \delta_{\varepsilon}$ and $\Delta \delta_{\gamma / \varepsilon}$ to the overall damping capacities measured at $165^{\circ} \mathrm{C}$ for $\mathrm{Fe}-17 \mathrm{wt} \% \mathrm{Mn}$ and $\mathrm{Fe}-21 \mathrm{wt} \% \mathrm{Mn}$ alloys. From the Table, it can be seen that the $\varepsilon$ martensite bears the major part of the damping capacities of $\mathrm{Fe}-17 \mathrm{wt} \% \mathrm{Mn}$ and $\mathrm{Fe}-21 \mathrm{wt} \% \mathrm{Mn}$ alloys.

\section{Conclusions}

(1) It is suggested that the damping sources responsible for damping capacities of Fe-Mn alloys containing $\gamma$ and $\varepsilon$ phases are: stacking fault boundary in $\gamma$, stacking fault boundary in $\varepsilon, \varepsilon$ martensite variant boundary, and $\gamma / \varepsilon$ interphase boundary.

(2) $\mathrm{Fe}-17 \mathrm{wt} \% \mathrm{Mn}$ alloy possesses the highest damping capacity in $\mathrm{Fe}-\mathrm{Mn}$ binary system. The reason is that the damping capacity of $\gamma$ single phase $\left(\delta_{\gamma}\right)$, the damping capacity due to $\gamma / \varepsilon$ interface $\left(\Delta \delta_{\gamma / \varepsilon}\right)$, and $\varepsilon$ martensite volume fraction $\left(f_{\varepsilon}\right)$ are larger in $\mathrm{Fe}-17 \mathrm{wt} \% \mathrm{Mn}$ alloy than the other $\mathrm{Fe}-\mathrm{Mn}$ alloys.

(3) The quantitative analysis of the damping capacity 
of $\mathrm{Fe}-17 \mathrm{Wt} \% \mathrm{Mn}$ alloy shows that the contributions of $\varepsilon$, $\gamma$ and $\gamma / \varepsilon$ interface to the overall damping capacity of the alloy are 83,14 and $3 \%$, respectively, indicating that $\varepsilon$ martensite bears the major part of the damping capacity of the $\mathrm{Fe}-17 \mathrm{wt} \% \mathrm{Mn}$ alloy.

\section{Acknowledgments}

This work was supported financially by Woojin OSK Corp., and the authors wish to thank President S. B. Lee for his financial support. The authors are also grateful to Dr. S. H. Baik of Woojin Research Institute of Measuring Technology for his helpful advices in this work.

\section{REFERENCES}

1) L. Wang and T. Ge: Phys. Status Solidi (a), 105 (1988), 447.

2) K. Sugimoto: J. Phys, 42 (1981), C5-971.

3) H. C. Lin, S. K. Wu and M. T. Yeh: Metall. Trans. A, 24A (1993), 2189.

4) H. Masumoto, M. Hinai and S. Sawaya: J. Jpn. Inst. Met., 51 (1987), 584.

5) K. Sugimoto: Tetsu-to-Hagane, 60 (1974), 127.

6) I. M. Sharshakov, V. N. Belko, V. S. Postnikov and D. Ye. Soldatenko: Fiz. Met. Metalloved, 28 (1969), 1084.
7) K. Matsui, A. Matsuno, F. Kizu, M. Takahashi and H. Kanno: J. Jpn. Inst. Met., 40 (1976), 1061.

8) C. S. Choi, J. D. Kim, T. H. Cho, S. H. Baik and G. H. Ryu: Proc. of ICOMAT-92, Monterey Inst. of Advanced Studies, Monterey, California, (1992), 509.

9) B. L. Averbach and M. Cohen: Trans. Metall. Soc. AIME, 176 (1948), 401.

10) J. Burke and D. W. Harvey: J. Iron Steel Inst., 208 (1970), 779.

11) W. H. Hatfield, G. Stanfield and L. Lotherham: Trans. N.E. Coast Inst. Engineers and Ship-builders, 63 (1942), 273.

12) H. Schumann: Z. Metallkd., 58 (1967), 207.

13) Z. Nishiyama: MARTENSITIC TRANSFORMATION, Academic Press, New York, (1978), 48.

14) J. H. Yang and C. M. Wayman: Proc. of ICOMAT-92, Monterey Inst. of Advanced Studies, Monterey, California, (1992), 1193.

15) S. Takaki, H. Nakatsu and Y. Tokunaga: Trans. Jpn. Inst. Met., 34 (1993), 489.

16) H. Schumann: Arch. Eisenhüttenwes., 38 (1967), 647.

17) Y. Tomota, M. Strum and J. W. Morris, Jr.: Metall. Trans. A, 18A (1987), 1073.

18) T. F. Volynova: Metalloved. Term. Obrab. Met., 6 (1984), 58.

19) H. Schumann: J. Kristall, U. Technik, 10 (1974), 1141.

20) P. H. Adler, G. B. Olson and W. S. Owen: Metall. Trans. A, 17A (1986), 1725.

21) J. H. Jun, W. Jin and C. S. Choi: Scr. Metall., 33 (I995), 1339.

22) T. Xiao and G. P. Johari: Metall. Trans. A, 26A (1995), 721.

23) L. J. Bruner: Phys. Rev., 118 (1960), 399. 